OPEN

SUBJECT AREAS:

CHEMICAL

ENGINEERING

ELECTROCHEMISTRY

BIOCATALYSIS

Received

21 October 2013

Accepted

25 April 2014

Published

13 May 2014

Correspondence and requests for materials should be addressed to S.F. (Shuji.Fujita@jp. sony.com)

\footnotetext{
* These authors contributed equally to this work.
}

\title{
A repeatedly refuelable mediated biofuel cell based on a hierarchical porous carbon electrode
}

\author{
Shuji Fujita, Shun Yamanoi*, Kenichi Murata*, Hiroki Mita, Tsunetoshi Samukawa, Takaaki Nakagawa, \\ Hideki Sakai \& Yuichi Tokita
}

Advanced Materials Laboratories, Sony Corporation, Atsugi-shi, Kanagawa 243-0021, Japan.

Biofuel cells that generate electricity from renewable fuels, such as carbohydrates, must be reusable through repeated refuelling, should these devices be used in consumer electronics. We demonstrate the stable generation of electricity from a glucose-powered mediated biofuel cell through multiple refuelling cycles. This refuelability is achieved by immobilizing nicotinamide adenine dinucleotide (NAD), an electron-transfer mediator, and redox enzymes in high concentrations on porous carbon particles constituting an anode while maintaining their electrochemical and enzymatic activities after the immobilization. This bioanode can be refuelled continuously for more than 60 cycles at $1.5 \mathrm{~mA} \mathrm{~cm}{ }^{-2}$ without significant potential drop. Cells assembled with these bioanodes and bilirubin-oxidase-based biocathodes can be repeatedly used to power a portable music player at $1 \mathrm{~mW} \mathrm{~cm}^{-3}$ through 10 refuelling cycles. This study suggests that the refuelability within consumer electronics should facilitate the development of long and repeated use of the mediated biofuel cells as well as of NAD-based biosensors, bioreactors, and clinical applications.

iofuel cells are expected to be next-generation energy devices capable of generating electricity from renewable fuels, such as sugars, alcohols and organic acids, using enzymes or microorganisms as catalysts ${ }^{1-5}$. Since these cells are lightweight (their construction requires minimal amounts of metal), easy to fuel (they use fuels that are readily available and have high energy density), and safe (they operate at neutral $\mathrm{pH}$ ), they are well suited for use in mobile consumer electronic devices, including portable music players and smart phones ${ }^{6}$. Compared to conventional secondary batteries and other fuel cells using platinum catalysts, biofuel cells using molecular catalysts do not tolerate repeated use very well. This is a significant disadvantage because reusability is a necessity for fuel cells ${ }^{6}$. The repeated use of biofuel cells is limited by the activity of the biocatalytic components. The activity of biofuel cells can be lost gradually by destabilization of the components or by leaching of the components from the cell electrode into solution. In the latter case, a significant portion of the catalytic components are removed from the cell when the fuel is exchanged for refuelling; the water from a glucose-based fuel, for example, is not consumed during operation and is replaced each cycle with the leached components. However, to the best of our knowledge, and despite the practicality of this feature, very few have investigated the refuelability of biofuel cells.

Several methods have been studied to reduce the leaching of electrode components. Covalent attachment of catalytic components (such as cofactors, electron transfer mediators and enzymes) to the electrode enables strong immobilization, however, this method often results in significant loss of the component's catalytic activity. For example, a covalent attachment of nicotinamide adenine dinucleotide (NAD), which is a versatile electrode component for many redox enzymes, has been used for many bioelectrocatalytic electrodes ${ }^{7,8}$. Though this compound was attached to several supports, attachment has been problematic because the bound NAD exhibited reduced activity. This reduced activity manifests as a loss of specificity for recognition by enzymes in particular using derivatives formed by adding functional groups to the NAD sugar backbone ${ }^{4,9-13}$. The covalent attachment of electron mediators based on the polymerization of an osmium complex has been successfully and widely applied, not only in biofuel cells, but also in biosensors, including those already being marketed ${ }^{14-17}$. To achieve sufficiently high power output of greater than $1 \mathrm{~mW} \mathrm{~cm}^{-3}$ in biofuel cells, much larger amounts of the redox moieties are required than are used in biosensors. The immobilization of large amounts of redox moieties is considered to be difficult to fabricate, expensive, and unsafe, since the osmium complex is rare and toxic. Direct electron transfer (DET) is another way to avoid the leaching of the mediator molecules. In a DET-based system, 
enzymes (typically in conjunction with a cofactor) directly transfer electrons to a metal or carbon electrode surface, so that small electron transfer mediator molecules are not required ${ }^{18-21}$. Without covalent bonding, some electrode materials, such as carbon nanotubes and three-dimensional structured composites, have shown strong adsorption for enzymes without significant loss of their activities $^{18,19,22-26}$. The implantable DET-based biofuel cells implemented with these carbonaceous materials show day-long continuous performances in animals ${ }^{27}$. Those nanofibers, however, are sometimes subject to scrutiny for safety concerns as they may produce environmental and human-health risks, including carcinogenesis ${ }^{28}$. The DET is currently limited to the use of specific enzymes, and some of the enzymes exhibit a decrease of cell voltage due to an overpotential. Furthermore, it is difficult to sequentially oxidize molecules of fuel in the DET system. In contrast, a mediated electron transfer, like with coupled diaphorase (Di) and NAD system, enables multistaged oxidation of fuels with cofactor and mediater by sharing them in each step of oxidation. This process works with glucose since the sugar can be completely oxidized by a combination of enzymes and NAD in living cells ${ }^{29,30}$.

In this communication, we present a robust immobilisation of multiple biocatalytic components - especially NAD - on a carbon electrode by using a porous carbon material. This technique is highly practical since it is simple, low-cost, safe, robust, and offers good energy density. We further demonstrate the repeated reuse of a mediated biofuel cell constructed in this manner over a number of consecutive fuel exchanges and the powering of a portable music player with the biofuel cell.

\section{Results and Discussion}

We experimented with a mediated bioanode composed of the following catalytic components shown in Figure 1A: NAD-dependent glucose dehydrogenase (GDH), Di, NAD and the mediator anthraquinone-2-sulfonate (AQ2S). Previously, we reported a similar Dilinked system but with 2-amino-1,4-naphthoquinone (ANQ) as an electron mediator; here, AQ2S is used in this study since it has a more negative redox potential than $\mathrm{ANQ}^{31}$. This anode has an $E^{\circ}$ value of $-0.45 \mathrm{~V}$ vs. $\mathrm{Ag} \mid \mathrm{AgCl}$ based on the redox potential of $\mathrm{AQ}_{2} \mathrm{~S}^{32}$. As shown in Figure $1 \mathrm{~A}$, the two-electron oxidation of glucose in this cell is catalysed by GDH with $\mathrm{NAD}^{+}$. The NADH generated by this process is subsequently oxidized by AQ2S through $\mathrm{Di}$ and the reduced form of the mediator $\left(\mathrm{AQ} 2 \mathrm{SH}_{2}\right)$ is then oxidized on the electrode surface. In this study, we immobilized these catalytic components on hierarchical porous carbon (HPC) to fabricate an anode with sufficient conductivity for electron flow from the glucose to the carbon electrode connected to an outer circuit. We have previously developed an HPC-based material formed from rice husks containing a high concentration of silica dioxide particles inside their cells ${ }^{33}$. This HPC was found to contain both micropores, with diameters less than $2 \mathrm{~nm}$, and mesopores, with diameters ranging from 2 to $50 \mathrm{~nm}$, resulting from the removal of silicate particles by hydrofluoric acid treatment. HPC also has a unique pore distribution compared to conventional porous carbons and exhibits both high specific surface area and large specific pore volume: $2 \times 10^{3} \mathrm{~m}^{2}$ $\mathrm{g}^{-1}$ and $2 \mathrm{~cm}^{3} \mathrm{~g}^{-1}$, respectively (Supplementary Figure S1). In prior work, we examined an anode electrode fabricated from HPC on which biocatalytic components were immobilized, since HPC was found to effectively adsorb several chemical compounds within its micropores and mesopores ${ }^{33}$. We expected that micropores and small mesopores $(<10 \mathrm{~nm}$ in size) would adsorb small molecules $(<1 \mathrm{~nm}$ in size), including NAD and mediators, and that large mesopores $(>10 \mathrm{~nm}$ ) adjacent to the small pores would be readily accessed by enzymes in the ranges 3 to $5 \mathrm{~nm}$. Based on these assumptions, we theorized that enzymes located in the large pores would readily interact with species such as NAD immobilized in the small pores (Figure 1B). We fabricated a bioanode with the HPC by first casting an HPC slurry in water on a carbon fibre sheet and drying the sheet at $120^{\circ} \mathrm{C}$ for $3 \mathrm{~h}$, afterwards, NADH and AQ2S were loaded onto the electrode. $N$-hydroxysuccinimide-activated pyrene was subsequently loaded onto the electrode for effective immobilization of the enzymes, and then GDH and Di were added. The anode was coated with glutaraldehyde-cross-linked poly-Llysine (PLL) to hold the HPC on the carbon fibre. In this study we used powdered HPC with an average particle size of approximately $4 \mu \mathrm{m}$ (Supplementary Figure S2). We also prepared an electrode using carbon black particles instead of HPC as a control. The HPC electrode had a high specific surface area of more than $1.5 \times$ $10^{3} \mathrm{~m}^{2} \mathrm{~g}^{-1}$, whereas the control electrode had a smaller specific surface area of less than $50 \mathrm{~m}^{2} \mathrm{~g}^{-1}$, as measured by nitrogen gas adsorption isotherms. The specific pore volume of the HPC decreased upon addition of AQ2S and NAD (Figure 1C), on immobilization of $1.3 \mathrm{~g}$ of AQ2S and $1.5 \mathrm{~g}$ of NAD per gram of HPC electrode mass ( $0.26 \mathrm{~g} \mathrm{HPC}$ and $0.74 \mathrm{~g}$ carbon fibre sheet). This decrease in the nitrogen adsorption of the micro and mesopores indicates that NAD and AQ2S occupied a substantial quantity of the pores, as predicted. Importantly, the HPC was found to hold those small molecules by 10 times higher mass than itself. To estimate the quantity of immobilized, electrochemically-active AQ2S molecules, we performed coulometric measurements using an HPC electrode loaded with $4.1 \mu \mathrm{mol} \mathrm{cm} \mathrm{cm}^{-2} \mathrm{AQ} 2 \mathrm{~S}$ as the input. We applied a voltage of $-0.65 \mathrm{~V}$ vs. $\mathrm{Ag} \mid \mathrm{AgCl}$ for $5 \mathrm{~min}$ in $1 \mathrm{M}$ phosphate buffer to completely reduce AQ2S to $\mathrm{AQ}_{2} \mathrm{SH}_{2}$, after which coulometry was carried out at $0 \mathrm{~V}$ vs. $\mathrm{Ag} \mid \mathrm{AgCl}$ to monitor the cathodic current during the oxidation of $\mathrm{AQ} 2 \mathrm{SH}_{2}$ back to AQ2S. Figure 1D presents the coulometric curve after subtracting a background obtained without AQ2S. This cathodic current does not include current originating from the auto-oxidation of $\mathrm{AQ} 2 \mathrm{SH}_{2}$ by oxygen, which can lead to overestimation. The results indicated that an AQ2S concentration of at least $2.8 \mu \mathrm{mol} \mathrm{cm} \mathrm{cm}^{-2}$ AQ2S (equivalent to $70 \%$ of the amount initially loaded) was immobilized in the pores and remained electrochemically active at the carbon surface. Figure 1E shows a scanning electron microscopy image of the HPC anode with a rigid coating of biocatalytic components covered by PLL: elements from the immobilized species were measured by EDX (Supplementary Figure S3).

This electrode was assembled into a working electrode, incorporating a titanium mesh as an electrical collector, Pt wire as the counter electrode and a $\mathrm{Ag} \mid \mathrm{AgCl}$ reference electrode (Supplementary Figure $\mathrm{S} 4)^{6}$. This electrode had a maximum catalytic current of $3.1 \mathrm{~mA} \mathrm{~cm}^{-2}$ measured by cyclic voltammetry; the catalytic current rose at less than $-0.45 \mathrm{~V}$ (Figure $2 \mathrm{~A}$ ). We assessed a rate-limiting factor of bioelectrocatalytic performance for the anode by varying the composition of catalytic components (Figure 2B). We believe the optimal amount of enzyme is the amount described as above: with additional enzymes, the catalytic current increased only slightly, however, the current decreased significantly upon reducing the enzymes, especially $\mathrm{Di}$. This behaviour indicates that the current enzyme concentration is optimal both for performance and cost. Moreover, a decrease in immobilized NAD did not decrease the current. These results suggest that the enzymatic composition of our biofuel cell is sufficient to saturate the catalytic current and that other factors limit the performance. We also estimated a diffusionlimited maximum current for the substrate (Figure 2C). The estimated current of $4 \mathrm{~mA} \mathrm{~cm}^{-2}$ suggests that the catalytic current of the HPC anode is not limited by diffusion. The rate-limiting factor(s) is not clear at present, although conditions such as $\mathrm{pH}$ and proton diffusion at the surface of the electrode may play a role. We also tested an anode fabricated with different HPCs annealed at $1400^{\circ} \mathrm{C}$, instead of $800^{\circ} \mathrm{C}$, changing the total pore volume and the sheet resistance, but not the size distribution of pores (Supplementary Figure S5). This HPC showed a similar bioelectrocatalytic performance to that of $800^{\circ} \mathrm{C}$ (Supplementary Figure S5C). 
A

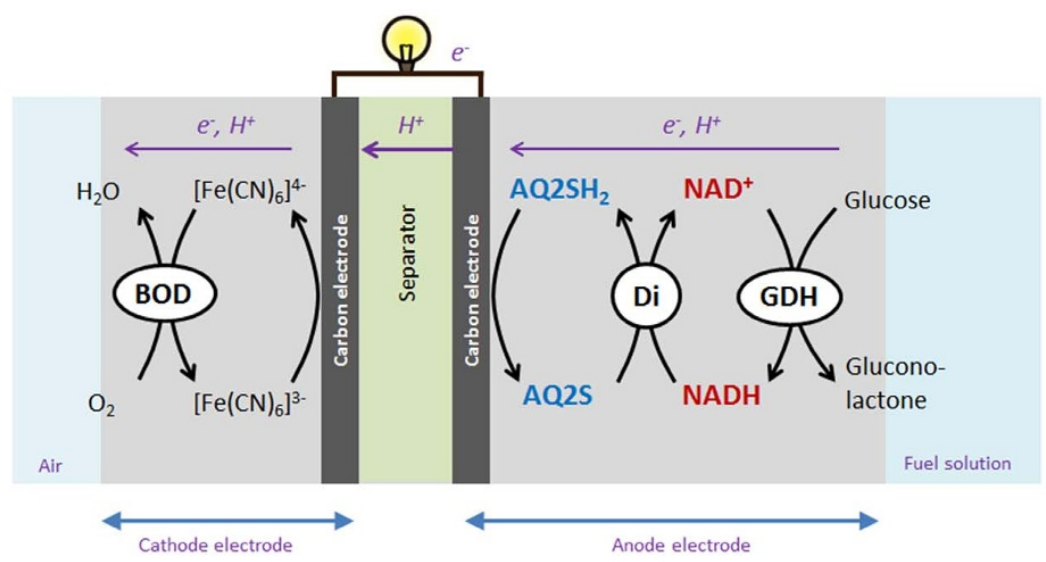

B

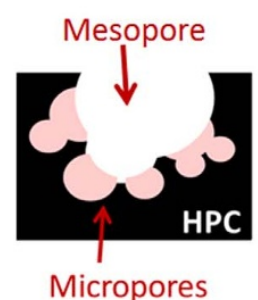

$\downarrow$

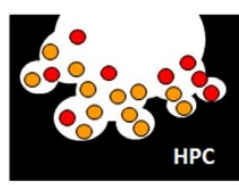

$\downarrow$

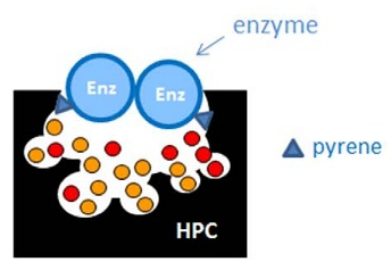

C

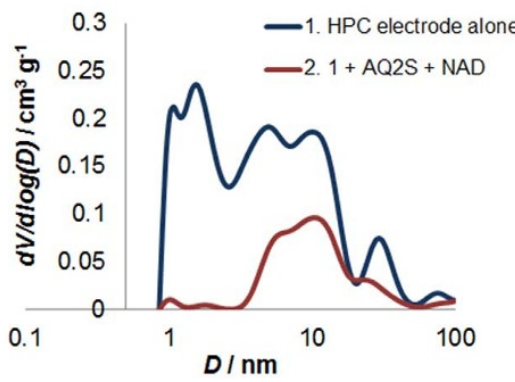

D

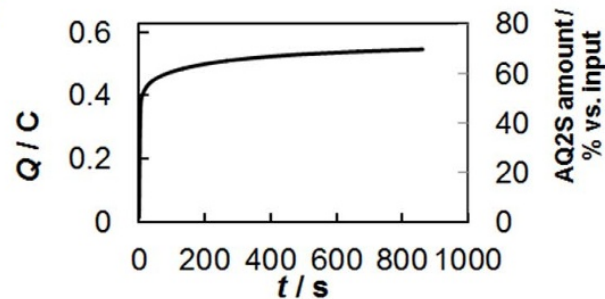

E

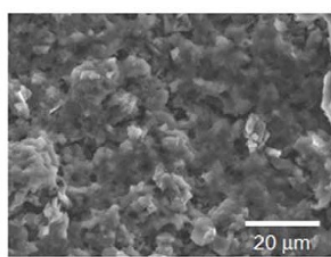

Figure $1 \mid$ Our biofuel cell system with the HPC anode. (A) Reaction scheme for bioelectrocatalysis of glucose via a mediated bioanode and biocathode system. The purple arrows indicate electron and proton flow. Electrons are transfered from glucose to the carbon electrode in anode and from the carbon electrode to oxygen in cathode. Protons are transferred from the anode to cathode through the separator of woven-fabric paper. (B) Diagrams showing the immobilization of biocatalytic components in HPC. (C) Immobilization of AQ2S and NADH in HPC pores as determined via nitrogen adsorption isotherms. Note that the pore volumes decrease upon addition of AQ2S and NADH. (D) Coulometry of AQ2S immobilized on an HPC electrode. (E) The surface of the HPC anode was imaged by SEM. The white scale bar indicates $20 \mu \mathrm{m}$.

Galvanostatic experiments of these anodes were performed at $1.5 \mathrm{~mA} \mathrm{~cm}^{-2}$ using $3 \mathrm{~mL}$ of fuel solution, the maximum capacity of the fuel container. The fuel solution consisted of $1.0 \mathrm{M}$ phosphate buffer at $\mathrm{pH} 7.0$ containing $0.8 \mathrm{M}$ glucose. We exchanged the fuel solution at $5 \mathrm{~min}$ intervals throughout the experiment. Figure $3 \mathrm{~A}$ presents the potential versus time $(V-t)$ curves for the HPC electrode and the control electrode. The spikes in this figure indicate the points at which fuel exchanges occurred. In the case of the control electrode, the potential dropped significantly following the first few fuel exchanges - the electrode was no longer able to generate $1.5 \mathrm{~mA}$ $\mathrm{cm}^{-2}$ because of the loss of catalytic activity. In contrast, it is evident that the HPC electrode was highly stable and was able to maintain approximately the same potential over more than 60 fuel exchanges, exhibiting only a slight potential drop from -0.4 to $-0.35 \mathrm{~V}$. The HPC electrode also showed only slight leaching of catalytic components, losing less than $10 \%$ of the NADH and AQ2S after multiple exchanges of the fuel solution (Figure $3 \mathrm{~B}$ and $3 \mathrm{C}$ ). Conversely, these compounds readily leached from the control electrode. Leaching was mainly observed in the early cycles, although very slight leaching might have occurred continuously and affected the stability of anode potential. The initial leaching from the HPC may be attributed to remnant molecules adsorbed on the surface of the HPC rather than trapped in the pores. The results indicate that the immobilized molecules retained their electrochemical and biocatalytic reactivity; we 
A

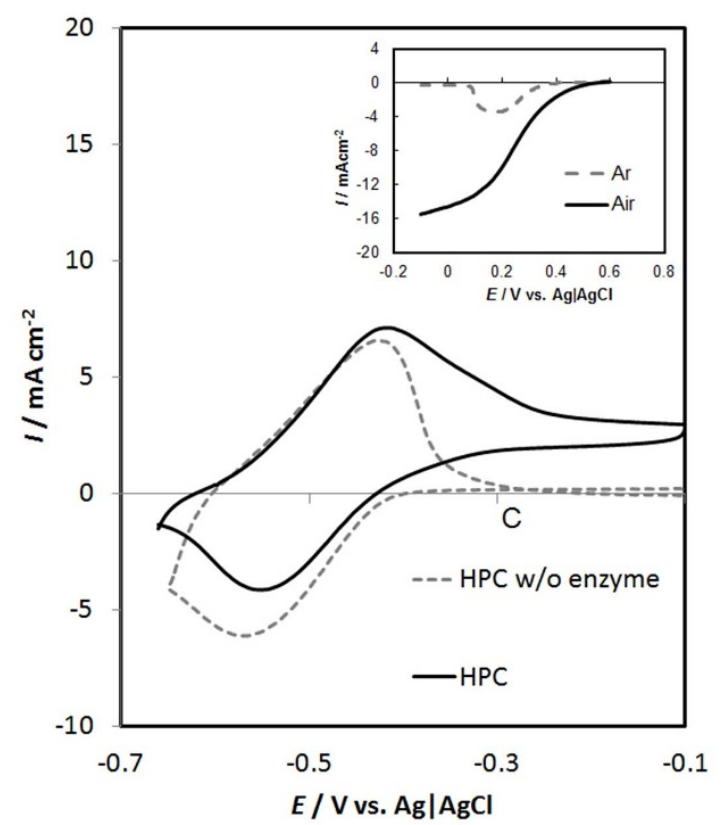

B
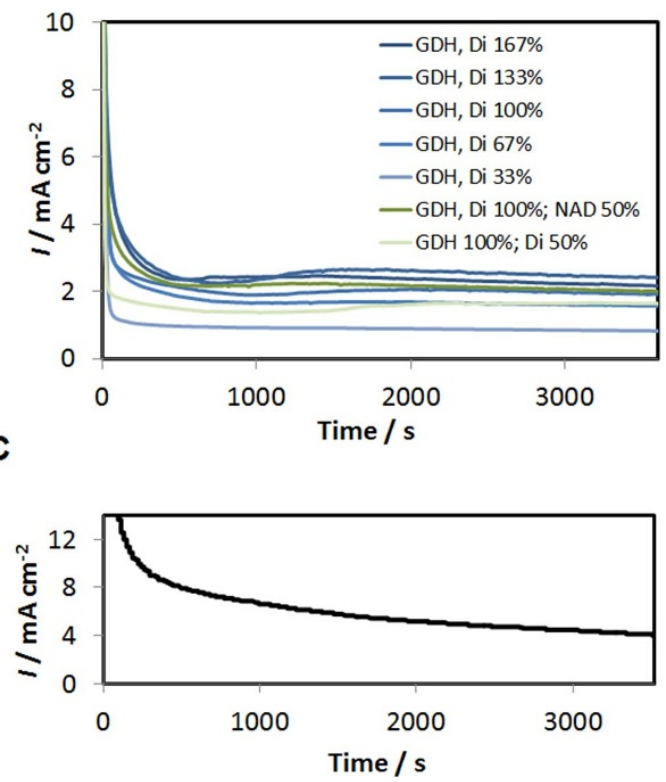

Figure 2 Bioelectrocatalytic performance of the HPC anode. (A) Cyclic voltammograms of the HPC anode. The potential of the working electrode were swept at $1 \mathrm{mV} \mathrm{s}^{-1}$ in $1.0 \mathrm{M}$ phosphate buffer containing $0.8 \mathrm{M}$ Glucose at $\mathrm{pH}$ 7.0. A solid line shows the voltammograms of HPC anode, and a dashed line shows that without enzymes as background. An inlet figure shows linear sweep voltammograpms of the cathode used in this study; a solid line shows the voltammograms of the cathode under air, and a dashed line shows that under argon as background. (B) $I$ - $t$ curves of the HPC anodes with different compositions of the biocatalytic molecules from two averaged independent potentiostatic measurements at $-0.4 \mathrm{~V} \mathrm{vs}$. Ag $\mid \mathrm{AgCl}$ in $1.0 \mathrm{M}$ phosphate buffer containing $0.8 \mathrm{M}$ Glucose at $\mathrm{pH}$ 7.0. The curve 'GDH, Di 100\%' indicates data for the anode used predominantly in this study. After increasing the amount of GDH and Di by more than 100\%, the current did not increase. On the other hand, less enzyme lead to a significantly suppressed current (e.g. $33 \%$ of the amount, curve 'GDH, Di 33\%'). When the Di was decreased by $50 \%$, we observed a significant decrease in the current. A decrease in the amount of NAD did not materially affect the current. (C) An $I$ - $t$ curve of an oxidation of ferrocyanide at $-0.4 \mathrm{~V}$ in $1.0 \mathrm{M}$ phosphate buffer containing $0.8 \mathrm{M}$ Glucose at $\mathrm{pH}$ 7.0. The diffusion-limited current at 1 hour after measurement is considered to be $4 \mathrm{~mA} \mathrm{~cm} \mathrm{c}^{-2}$ based on this curve.

observed that AQ2S loaded at a concentration of $2.8 \mu \mathrm{mol} \mathrm{cm}{ }^{-2}$ was highly immobilized on the carbon surface and yet still retained its original electrochemical reactivity (see Figure 1D and Supplementary Figure S6). The mediator species can be immobilized on the HPC electrode at a density similar to or greater than using traditional polymerization techniques, while retaining its electrochemical reactivity, even though the HPC electrodes are carbon-based rather than made of metals such as gold ${ }^{34,35}$. Furthermore, more than $90 \%$ of the enzymes were strongly anchored to the HPC surface through amide coupling with the pyrene groups that were immobilised on the HPC sufaces before the coupling with enzymes (Figure 3D and 3E). Although the pyrene-mediated immobilization of proteins on carbon nanotubes is well established ${ }^{36-38}$, this phenomenon evidently also provides an effective means of immobilizing proteins on porous carbons whose pores are filled with other molecules. The apparent rate constants of the immobilized GDH and Di were calculated as $2 \mathrm{~s}^{-1}$ and $8 \mathrm{~s}^{-1}$ from the catalytic current, $3.1 \mathrm{~mA} \mathrm{~cm}^{-2}$. These rates were an order of magnitude less than those in solution. Some immobilized enzymes may have little or no activity because of molecular orientation, being far apart from NAD and AQ2S, and degradation while immobilized. The coating of the electrode surface with PLL cross-linked by glutaraldehyde, as observed in Figure 1E, effectively prevented the HPC particles from detaching from the carbon fibre sheet due to agitation associated with fuel exchanges, even though solution pipetting was performed close to the surface of the electrode. This rigid coating of the carbon particles might also be useful in other applications where the integrity of carbon particles must be maintained on surfaces and supports in contact with an agitated solution.

We next examined the performance of a cell incorporating the HPC anode via galvanostatic measurements. A test cell was assembled with an HPC anode and a biocathode utilizing bilirubin oxidase (BOD), which catalyses a reduction of oxygen to water at neutral $\mathrm{pH}$ with electrons from the anode through an external circuit. The cathode reaction was mediated by using ferricyanide as an electron transfer mediator; this mediator is convenient to use because it is inexpensive, stable, and safe (Figure 1A). Based on our previous development work, we fabricated a sink-type biocathode that enables electrocatalysis with charge generation on the order of several $\mathrm{mA}$ $\mathrm{cm}^{-26,39}$. A water-repelling treatment of the cathode improves its maximum catalytic current to more than $15 \mathrm{~mA} \mathrm{~cm}^{-2}$ under air atmosphere, and enables more than $1.5 \mathrm{~mA} \mathrm{~cm}^{-2}$ of catalytic current at $+0.4 \mathrm{~V}$ (Figure $2 \mathrm{~A})^{39}$. Since the cathode had a maximum catalytic current of $15 \mathrm{~mA} \mathrm{~cm}^{-2}$, nearly five times larger than $3.1 \mathrm{~mA} \mathrm{~cm}^{-2}$ of the anode, the performance of the anode was the rate-limiting component of the cell. Both electrodes were connected by a Ti mesh for current collection and a portion of non-woven paper was inserted between the anode and cathode as a separator. A polytetrafluoroethylene film was placed on the exterior of the cathode to serve as an oxygen-permeable layer without allowing fuel to leak out (Supplementary Figure S4B). The measurements were performed at $1.5 \mathrm{~mA} \mathrm{~cm} \mathrm{~m}^{-2}$ using $3 \mathrm{~mL}$ of fuel solution consisting of $1.0 \mathrm{M}$ phosphate buffer at $\mathrm{pH} 7.0$ containing $0.8 \mathrm{M}$ glucose. This fuel solution was fully exchanged at $5 \mathrm{~min}$ intervals during the experiment; the short refuelling intervals avoided deleterious effects, including the destabilization of enzymes and interference from by-products. To focus on refuelling, we believed an accelerated test was warranted. The cell was found to consistently generate more than $1 \mathrm{~mW} \mathrm{~cm} \mathrm{~mW}^{-2}$ over 35 consecutive fuel exchanges, although the cell voltage decreased drastically from $0.6 \mathrm{~V}$ to less than $0.2 \mathrm{~V}$ after approximately 40 fuel exchanges (Figure 4A). Since we also independently 
A

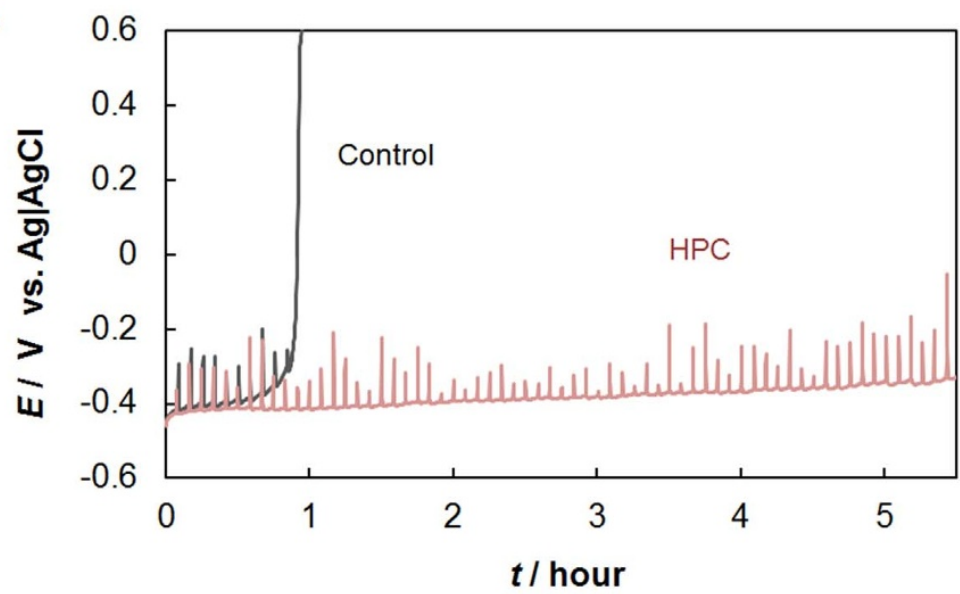

B

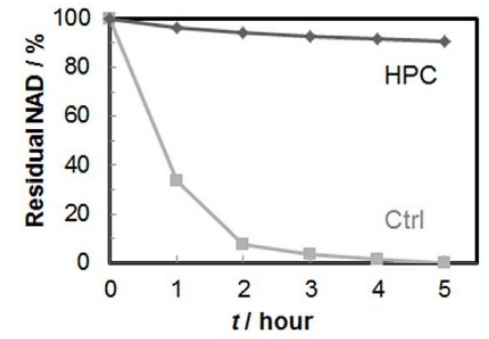

C

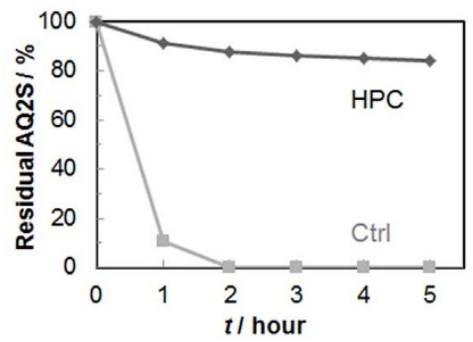

D

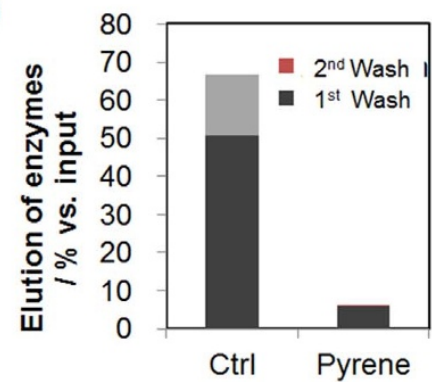

E

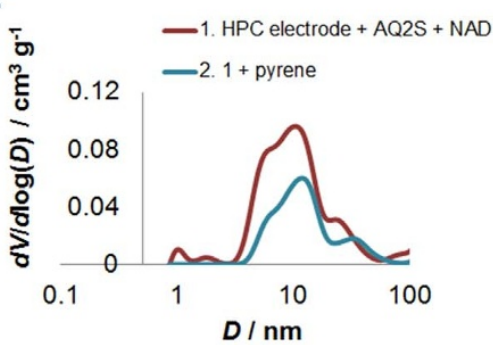

Figure 3 Refueling performance of the HPC anode. (A) Galvanostatic measurements of the anode with fuel exchange every 5 min. Measurements were performed at $1.5 \mathrm{~mA} \mathrm{~cm}{ }^{-2}$ in $1.0 \mathrm{M}$ phosphate buffer containing $0.8 \mathrm{M}$ glucose at $\mathrm{pH}$ 7.0. Spikes indicated fuel exchanges. (B) and (C) Leaching of immobilized mediator and NADH from both control and HPC electrodes. Remaining concentrations of NADH (upper panel) and AQ2S (lower panel) were estimated based on concentrations determined in the fuel solution via HPLC. (D) Elution of enzymes immobilized on an HPC electrode with or without NHS-pyrene. Eluted amounts were estimated from densitometry of silver-stained SDS-PAGE results against the input amount. (E) Adsorption of NHS-pyrene (which functions as an anchor for the enzyme) into the pores of HPC as monitored by nitrogen adsorption isotherms.

monitored the anode potential using a $\mathrm{Ag} \mid \mathrm{AgCl}$ reference electrode, we were able to obtain the cathode potential by subtracting the anode potential from the cell voltage (Figure 4B). We determined that the cathodic potential dropped in a manner similar to the observed decrease in the cell voltage, while the anode potential remained stable at approximately $-0.4 \mathrm{~V}$ throughout the measurement. Therefore, the drop in cell voltage is attributed to the decrease in cathodic potential. The rate-limiting factor associated with the cathode potential drop is not known at present, but possibilities include: leaching of ferricyanide, inactivation of the enzyme or loss of the access path by which oxygen or air enters the cathode due to infiltration of the fuel solution into that path. The leaching of ferricyanide was observed even though the amount was less than $10 \%$ of the input (Supplementary Information and Supplementary Figure S7). Cathodes made of the same HPC used in the anode was not effective because the ferricyanide did not adsorb to the HPC. This behaviour was expected: NAD and AQ2S pack well inside the HPC-based material because they are neutral or only weakly ionic, however, ferricyanide may not pack densely within the pores because it is strongly anionic. Since some of the adsorbed molecules also have aromatic moieties, $\pi-\pi$ interactions between the HPC surface and these molecules might be an important factor in their immobilization. Our HPC system makes use of this phenomenon since pyrene derivatives known to bind to the carbon surface via $\pi-\pi$ interactions adsorb strongly to the HPC surface and work to anchor the enzymes. In future work, based on careful consideration of these factors, it should be possible to efficiently screen for better mediators to use with HPC-based cathodes. We assembled a cell with a control anode made of standard carbon black with carbon fibres - a common electrode for biofuel cells - but the galvanostatic performance of this control cell dropped within less than ten cycles; the anodic potential dropped significantly as seen in the anodic test in Figure 3A (data not shown). We assessed the refuelling ability by refuelling the aforementioned device every 5 minutes. We also performed an experiment with a 2-hour refuelling interval to assess the long-term, continuous operability (Supplementary Figure S8). The cell with HPC anodes stably generated electricity for 10 hours. The voltage of the cells dropped after $10 \mathrm{~h}$, associated with the cathodic potential drop. This result suggests that long-term use of the biofuel cell requires an improved cathode, however, we believe that this range of performance can be an attractive 
A

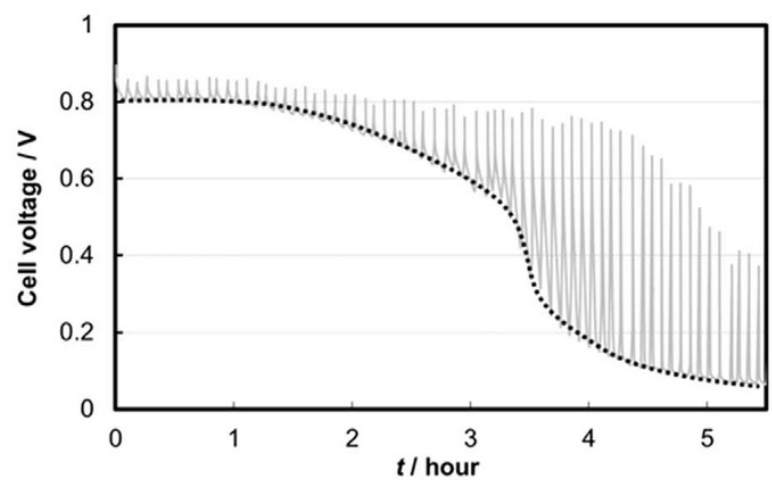

B

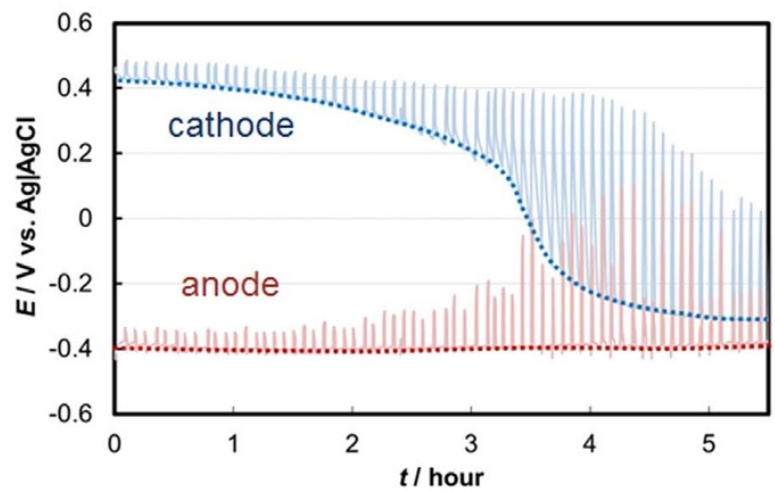

C

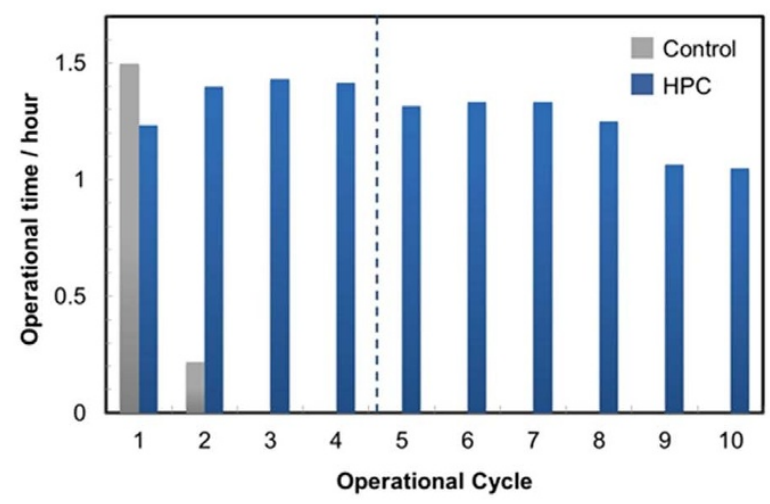

Figure $4 \mid$ Performance of the cell incorporating an HPC anode over multiple fuel exchanges. Galvanostatic measurements of the cell with fuel exchange every 5 min showing (A) cell voltage and (B) cathode and anode potentials vs. time. Measurements were performed at $1.5 \mathrm{~mA} \mathrm{~cm}{ }^{-2}$ in 1.0 $\mathrm{M}$ phosphate buffer containing $0.8 \mathrm{M}$ glucose at $\mathrm{pH}$ 7.0. Spikes indicate fuel exchanges and the dashed lines show the course of average values at 5 min intervals. (C) Repeated operation of the Walkman ${ }^{\circledR}$ device based on refuelling with buffered Coca-Cola ${ }^{\circledR}$. Each time the device ran out of power, we exchanged the fuel with fresh buffered Coca-Cola ${ }^{\circledR}$ and restarted it. The dashed vertical line indicates the start of the $2^{\text {nd }}$ day. At the end of 1st day, the cell was thoroughly washed with pure water.

starting point to construct biofuel cells for week-long to month-long operation. More importantly, our biofuel cells demonstrated the stable, day-long generation of electricity at more than $1 \mathrm{~mW} \mathrm{~cm}{ }^{-2}$, even with refuelling and vigorous flushing. Several groups recently demonstrated new biocatalytic electrodes that produce high catalytic current over a long period of time. Stable power generations with those electrodes, however, were not shown; the cell performance is governed by multiple factors and not simply determined by the performances of the anode or cathode alone $\mathrm{e}^{22,23,40}$.

Our primary purpose was to develop a practical biofuel cell for consumer electronic devices and we therefore attempted to continually power a Sony Walkman ${ }^{\circledR}$ mp3 music player using these cells.
Our approach was to employ three cells stacked in series, each in a $6 \mathrm{~mL}$ fuel container filled with Coca-Cola ${ }^{\circledR}$, using the anode and the cathode electrodes described above, to generate $1 \mathrm{~mW} \mathrm{~cm}-3$ of power. The Walkman ${ }^{\circledR}$, thus, powered by these cells, operated continuously through 10 cycles of refuelling with Coca-Cola ${ }^{\circledR}$ while playing music through passive speakers that were also powered by the biofuel cells through the Walkman ${ }^{\circledR}$ (Figure 4C). When powered by the control biofuel cells, the Walkman ${ }^{\circledR}$ worked during the first cycle and stopped working 10 minutes into the $2^{\text {nd }}$ cycle. The HPCbased biofuel cells were stable throughout the refuelling cycles, even though the fuel was exchanged 10 times and each refuelling process involved vigorous agitation of the fuel solution close to the electrode surface, and relatively rough handling. The Walkman ${ }^{\circledR}$ was found to stop playing when the glucose concentration in the fuel solution was depleted to approximately half the starting concentration. We cannot explain this behaviour at present, but, we believe that there could be several explanations: i) a decrease of glucose flux to the anode, ii) a localized high or low $\mathrm{pH}$ conditions at the cathode or anode, respectively, outweighing the buffering capacity and proton transfer or iii) an inhibition of the reaction by an accumulation of a reaction product or by-product, like gluconolactone or peroxide. These detrimental effects disappear when the fuel is replenished with vigorous mixing. When the device was about to run out of power, we observed that the $\mathrm{pH}$ of the fuel solution decreased to approximately 6.0, but recovered to $\mathrm{pH} 7.0$ after refuelling. We also found that the cells maintained their performance even when washed vigorously with water and dried overnight at ambient temperature. The operation lengths were slightly reduced at the $9^{\text {th }}$ and $10^{\text {th }}$ cycles, compared to the initial cycles. This reduced performance may be explained by cathodic degradation. We expect that the ability of these cells to withstand washing and storage will greatly increase their practicality. Despite our best efforts, similar, commercially available biofuel cells were not available as a comparison. A few educational experimental kits of microbial biofuel cells are commercially available, such as MudWatt ${ }^{\mathrm{TM}}$, however they are not powered by glucose and they suffer from several limitations: low power output (less than $1 \mu \mathrm{W} \mathrm{cm}{ }^{-3}$ ), long wait time to generate electricity (around a week), uncontrollable supply of microorganisms as catalyst from soil, and difficulty to replace soil. We believe that the biofuel cell presented could serve as a foundation for biofuel cells that can be used in consumer electronics devices.

\section{Conclusions}

In this study, we developed a glucose-based mediated biofuel cell that was refuelable repeatedly. We accomplished this cell by the electrochemically and enzymatically active and robust immobilization of mediator, cofactor and enzymes on a carbon electrode with porous carbon particles. This immobilization technique will likely have applications to electrochemical devices, such as biofuel cells and biosensors, but also for heterogeneous catalysis. This is a particularly important discovery for NAD since covalent immobilization techniques have often resulted in decreased activity with enzymes. Although non-covalent immobilization of NAD using CNTs was recently reported ${ }^{41}$, the large quantity of immobilized NAD, by our method, would be widely applicable for the design of reactors, columns, biosensors, diagnostic tools and medical treatments ${ }^{10,11,27,42-45}$. With this processing technique, we have demonstrated successfully the stable performance of a mediated bioanode at a current level of $1.5 \mathrm{~mA} \mathrm{~cm}^{-2}$ over 50 consecutive refuelling cycles (Fig. $3 \mathrm{~A}$ and $4 \mathrm{~B}$ ). Importantly, our refuelable, mediated bioanode may be improved to allow the further oxidation of glucose to $\mathrm{CO}_{2}$ since it utilizes NAD, a versatile cofactor in the glycolysis process in living cells ${ }^{30,46-48}$. The immobilization of both AQ2S and Di in this bioanode thus facilitates the transfer of electrons to the electrode via multiple enzymatic reactions. Our method of immobilization is simple: aqueous solutions are added to inexpensive carbon materials for less than 1 hour, eliminat- 
ing concerns about cost and manufacturability even if using multiple biocatalytic components. This biofuel cell also demonstrated promising durability - it can be refuelled repeatedly to generate sufficient electricity to continuously power both the Walkman ${ }^{\circledR}$ device and the connected mobile loud speakers simultaneously (Fig. 4C). We believe that this improved durability is an important step towards the application of biofuel cells in consumer electronics devices, and will greatly facilitate the development of biofuel cells with performance levels suitable for practical applications, like a mobile charging device.

\section{Methods}

Materials. GDH (EC 1.1.1.47) was purchased from Toyobo (Osaka, Japan), Di (EC 1.8.1.4), and bilirubin oxidase (EC 1.3.3.5) from Myrothecium sp. were purchased from Amano Enzyme (Nagoya, Japan) and NAD and AQ2S were purchased from Oriental Yeast (Tokyo, Japan) and Tokyo Chemical Industry (Tokyo, Japan), respectively. PLL used for construction of the anode (MW $>300,000)$, glutaraldehyde and 1-pyrenebutyric acid N-hydroxysuccinimide ester (NHS-pyrene) were all purchased from Sigma Aldrich (St. Louis, MO, USA). PLL used for the cathode (Mw approximately 8000) was purchased from Peptide Institute Inc., Ltd. (Osaka, Japan). Glucose, potassium ferricyanide and phosphate buffer were purchased from Wako (Osaka, Japan). All other chemicals were of reagent grade quality.

Preparation of HPC. A $50 \mathrm{~g}$ quantity of rice husks was carbonized in a furnace for $1 \mathrm{~h}$ at $800^{\circ} \mathrm{C}$ under nitrogen atmosphere to prepare the silica-carbon composite (yield: $17 \mathrm{~g}$ or $34 \%$ ). A 10 g portion of this composite was stirred in $46 \%$ hydrofluoric acid solution at room temperature for $12 \mathrm{~h}$ to remove the silica and fabricate the macroporous structure. Following this step, the resulting porous carbon (PC) material was thoroughly washed with pure water and ethanol (yield: approximately $6 \mathrm{~g}$ or $60 \%)$. HPC was obtained by steam activation of $2.5 \mathrm{~g}$ of the PC for $3 \mathrm{~h}$ at a flow rate of $250 \mathrm{~mL} \mathrm{~min}^{-1}$ (yield: $1.2 \mathrm{~g}$ or $56 \%$ ) and the resulting $\mathrm{HPC}$ was pulverized to an average particle size of $4 \mu \mathrm{m}$.

Preparation of the HPC electrode. The HPC produced by the above process was added to a carbon fibre sheet (approximately $300 \mu \mathrm{m}$ thickness) at a concentration of $3.6 \mathrm{mg} \mathrm{cm}^{-2}$, followed by the addition of $1.2 \mathrm{mg} \mathrm{cm}^{-2}$ AQ2S and $1.5 \mathrm{mg} \mathrm{cm}^{-2} \mathrm{NAD}$. NHS-pyrene was subsequently added to the electrode at $0.3 \mathrm{mg} \mathrm{cm}^{-2}$, followed by $0.9 \mathrm{mg} \mathrm{cm}^{-2} \mathrm{GDH}$ and $0.1 \mathrm{mg} \mathrm{cm}^{-2} \mathrm{Di}$. After incubation at $40^{\circ} \mathrm{C}$ for up to $1 \mathrm{~h}$, the electrode was coated with $0.5 \mathrm{mg} \mathrm{cm}^{-2}$ PLL and $0.03 \mathrm{mg} \mathrm{cm}^{-2}$ Glutaraldehyde.

Adsorption isotherm experiment. Glass tubes containing $50 \mathrm{mg}$ of the bare carbon particles or carbon particles loaded on carbon fibre were inserted into a BELSORPMax (BEL Japan Inc.) apparatus, together with a blank tube, followed by heat treatment for $3 \mathrm{~h}$ at $300^{\circ} \mathrm{C}$. Adsorption measurements were performed in liquid nitrogen using pure nitrogen gas $(>99.99995 \%)$ and pore size distributions were calculated on the basis of the non-linear density functional theory (NLDFT) using BELSim software (BEL Japan Inc.)

High Performance Liquid Chromatography (HPLC) analysis. Liquid chromatography was performed on a Waters Alliance 2690 system using the following parameters. Column: XBridge phenyl (Waters), flow rate: $0.4 \mathrm{~mL} \mathrm{~min}{ }^{-1}$, mobile phase: water/methanol $(\mathrm{v} / \mathrm{v}=1)$, detector: $U V-V i s(\lambda=300 \mathrm{~nm})$.

Sodium dodecyl sulphate-Polyacrylamide gel electrophoresis (SDS-PAGE). Samples were boiled for $10 \mathrm{~min}$ in a standard SDS buffer and were subsequently separated in a $15 \%$ polyacrylamide gel at $200 \mathrm{~V}$, followed by silver staining (Bio-Rad). Densitometry of the stained gel was performed using the ImageJ program.

Secondary Electron Microscopy (SEM) and Energy dispersive X-ray spectroscopy (EDX). The HPC anode was directly set on stage in the chamber of SEM (S-3400, Hitachi), and then imaged at $15 \mathrm{kV}$ of accelerating voltage under less than $0.1 \mathrm{~Pa}$ at room temperature. Element mapping was performed using the same sample by EDX implemented in the S-3400.

Electrochemical measurements. (i) Bioanode measurements. An electrochemical cell for testing of the bioanode was assembled using an acrylic chassis with a titan mesh as the electrical collector, in a manner similar to a previously reported apparatus ${ }^{6}$. CV and galvanostatic measurements were performed using a $1480 \mathrm{Multi}$ Stat (Solartron Analytical) in a three-electrode system without forced convection at room temperature, in which the bioanodes were used as the working electrode (W.E.). A Pt wire and a $\mathrm{Ag}|\mathrm{AgCl}|$ sat. $\mathrm{KCl}$ electrode were used as the counter electrode (C.E.) and reference electrode (R.E.), respectively. The measurements were performed in a $1.0 \mathrm{M}$ phosphate buffer at $\mathrm{pH} 7$ containing $0.8 \mathrm{M}$ glucose. (ii) Cell measurements. We constructed a passive-type biofuel cell in which a paper was sandwiched between the bioanode and the biocathode to prevent electrical contact between them. The electrochemical analyses were performed using this same apparatus. (iii) The test for the Walkman ${ }^{\circledR}$. The three cells were stacked in series to power the memory-type Walkman ${ }^{\circledR}$ (NW-E042, Sony) at $1 \mathrm{~mW} \mathrm{~cm}^{-3}$ of average power density. A fresh roomtemperature Coca-Cola ${ }^{\circledR}$ buffered with $1.0 \mathrm{M}$ phosphate buffer at $\mathrm{pH} 7.0$ was used as a fuel. The music was played by an auto-repeat mode with the passive speakers system (SRS-P11Q, Sony), which was powered by Walkman, at a middle volume.

1. Ikeda, T. \& Kano, K. An electrochemical approach to the studies of biological redox reactions and their applications to biosensors, bioreactors, and biofuel cells. J. Biosci. Bioeng. 92, 9-18 (2001).

2. Barton, S. C., Gallaway, J. \& Atanassov, P. Enzymatic biofuel cells for Implantable and microscale devices. Chem. Rev. 104, 4867-4886 (2004).

3. Logan, B. E. et al. Microbial fuel cells: Methodology and technology. Environ. Sci. Technol. 40, 5181-5192 (2006).

4. Willner, I., Yan, Y. M., Willner, B. \& Tel-Vered, R. Integrated Enzyme-Based Biofuel Cells-A Review. Fuel Cells 9, 7-24 (2009).

5. Leech, D., Kavanagh, P. \& Schuhmann, W. Enzymatic fuel cells: Recent progress. Electrochim. Acta 84, 223-234 (2012).

6. Sakai, H. et al. A high-power glucose/oxygen biofuel cell operating under quiescent conditions. Energy Environ. Sci. 2, 133-138 (2009).

7. Gorton, L., Domı, amp, x \& nguez, E. Electrocatalytic oxidation of NAD(P)H at mediator-modified electrodes. Reviews in Molecular Biotechnology 82, 371-392 (2002).

8. Gorton, L. \& Bartlett, P. N. NAD(P)-Based Biosensors in Bioelectrochemistry 157-198 (John Wiley \& Sons, Ltd, 2008).

9. Schmidt, H. L. \& Grenner, G. Coenzyme properties of NAD + bound to different matrices through the amino group in the 6-position. Eur. J. Biochem. 67, 295-302 (1976).

10. Hiroyuki Ukeda, K. O., Masatomo Imabayashi, Kiyoshi Matsumoto \& Yutaka Osajima. Direct Immobilization of NAD to Sepharose 4B by Using the Bifunctional Reagent Glutaraldehyde. Agric. Biol. Chem. 53, 235-237 (1989).

11. Hendle, J., Buckmann, A. F., Aehle, W., Schomburg, D. \& Schmid, R. D. Structure/ activity relationship of adenine-modified NAD derivatives with respect to porcine heart lactate dehydrogenase isozyme $\mathrm{H} 4$ simulated with molecular mechanics. Eur. J. Biochem. 213, 947-956 (1993).

12. Bardea, A., Katz, E., Buckmann, A. F. \& Willner, I. NAD(+)-dependent enzyme electrodes: Electrical contact of cofactor-dependent enzymes and electrodes. J. Am. Chem. Soc. 119, 9114-9119 (1997).

13. Zhang, M., Mullens, C. \& Gorski, W. Coimmobilization of dehydrogenases and their cofactors in electrochemical biosensors. Anal. Chem. 79, 2446-2450 (2007)

14. Degani, Y. \& Heller, A. Electrical communication between redox centers of glucose oxidase and electrodes via electrostatically and covalently bound redox polymers. J. Am. Chem. Soc. 111, 2357-2358 (1989).

15. Mano, N., Mao, F. \& Heller, A. Characteristics of a Miniature Compartment-less Glucose-O2 Biofuel Cell and Its Operation in a Living Plant. J. Am. Chem. Soc. 125, 6588-6594 (2003).

16. Heller, A. Integrated medical feedback systems for drug delivery. AlChE J. 51, 1054-1066 (2005).

17. Zafar, M. N. et al. Electron-Transfer Studies with a New Flavin Adenine Dinucleotide Dependent Glucose Dehydrogenase and Osmium Polymers of Different Redox Potentials. Anal. Chem. 84, 334-341 (2011).

18. Cai, C. X. \& Chen, J. Direct electron transfer of glucose oxidase promoted by carbon nanotubes. Anal. Biochem. 332, 75-83 (2004).

19. Kamitaka, Y., Tsujimura, S., Setoyama, N., Kajino, T. \& Kano, K. Fructose/ dioxygen biofuel cell based on direct electron transfer-type bioelectrocatalysis. Phys. Chem. Chem. Phys. 9, 1793-1801 (2007).

20. Bartlett, P. N. Bioelectrochemistry: fundamentals, experimental techniques and applications 57-75 (John Wiley \& Sons, 2008).

21. Falk, M., Blum, Z. \& Shleev, S. Direct electron transfer based enzymatic fuel cells. Electrochim. Acta 82, 191-202 (2012).

22. Zebda, A. et al. Mediatorless high-power glucose biofuel cells based on compressed carbon nanotube-enzyme electrodes. Nat Commun 2, 370 (2011).

23. Gao, F., Viry, L., Maugey, M., Poulin, P. \& Mano, N. Engineering hybrid nanotube wires for high-power biofuel cells. Nat Commun 1, 2 (2010).

24. Hamano, Y., Tsujimura, S., Shirai, O. \& Kano, K. Micro-cubic monolithic carbon cryogel electrode for direct electron transfer reaction of fructose dehydrogenase. Bioelectrochemistry 88, 114-117 (2012).

25. Frasconi, M., Rea, S., Matricardi, P., Favero, G. \& Mazzei, F. Scleroglucan-Borax Hydrogel: A Flexible Tool for Redox Protein Immobilization. Langmuir 25, 11097-11104 (2009).

26. Yang, X.-Y., Tian, G., Jiang, N. \& Su, B.-L. Immobilization technology: a sustainable solution for biofuel cell design. Energy Environ. Sci. 5, 5540-5563 (2012).

27. Zebda, A. et al. Single Glucose Biofuel Cells Implanted in Rats Power Electronic Devices. Sci. Rep. 3 (2013).

28. Occupational Exposure to Carbon Nanotubes and Nanofibers, Vol. 145. (National Institute for Occupational Safety and Health, Centers for Disease Control and Prevention, 2013)

29. Chaudhuri, S. K. \& Lovley, D. R. Electricity generation by direct oxidation of glucose in mediatorless microbial fuel cells. Nat. Biotechnol. 21, 1229-1232 (2003).

30. Tsujimura, S. et al. Micro-coulometric study of bioelectrochemical reaction coupled with TCA cycle. Biosens. Bioelectron. 34, 244-248 (2012). 
31. Sugiyama, T. et al. A mediator-adapted diaphorase variant for a glucose dehydrogenase-diaphorase biocatalytic system. Biosens. Bioelectron. 26, 452-457 (2010)

32. Kano, K. Redox Potentials of Proteins and Other Compounds of Bioelectrochemical Interest in Aqueous Solutions. Rev. Polarog. 48, 29-46 (2002).

33. Tabata, S., Iida, H., Horie, T. \& Yamada, S. Hierarchical porous carbon from cell assemblies of rice husk for in vivo applications. MedChemComm 1, 136-138 (2010).

34. Raitman, O. A., Patolsky, F., Katz, E. \& Willner, I. Electrical contacting of glucose dehydrogenase by the reconstitution of a pyrroloquinoline quinonefunctionalized polyaniline film associated with an Au-electrode: an in situ electrochemical SPR study. Chem. Commun. 0, 1936-1937 (2002).

35. Zayats, M., Katz, E. \& Willner, I. Electrical Contacting of Glucose Oxidase by Surface-Reconstitution of the Apo-Protein on a Relay-Boronic Acid-FAD Cofactor Monolayer. J. Am. Chem. Soc. 124, 2120-2121 (2002).

36. Chen, R. J., Zhang, Y., Wang, D. \& Dai, H. Noncovalent sidewall functionalization of single-walled carbon nanotubes for protein immobilization. J. Am. Chem. Soc. 123, 3838-3839 (2001)

37. Besteman, K., Lee, J.-O., Wiertz, F. G. M., Heering, H. A. \& Dekker, C. EnzymeCoated Carbon Nanotubes as Single-Molecule Biosensors. Nano Lett. 3, 727-730 (2003).

38. Ramasamy, R. P., Luckarift, H. R., Ivnitski, D. M., Atanassov, P. B. \& Johnson, G. R. High electrocatalytic activity of tethered multicopper oxidase-carbon nanotube conjugates. Chem. Commun. 46, 6045-6047 (2010)

39. Nakagawa, T. et al. Water-repellent-treated enzymatic electrode for passive airbreathing biocathodic reduction of oxygen. Electrochem. Commun. 36, 46-49 (2013).

40. Wu, C. et al. A white-rot fungus is used as a biocathode to improve electricity production of a microbial fuel cell. Applied Energy 98, 594-596 (2012).

41. Zhou, H. et al. Noncovalent Attachment of NAD+ Cofactor onto Carbon Nanotubes for Preparation of Integrated Dehydrogenase-Based Electrochemical Biosensors. Langmuir 26, 6028-6032 (2010).

42. Chenault, H. K. \& Whitesides, G. M. Regeneration of nicotinamide cofactors for use in organic synthesis. Appl. Biochem. Biotechnol. 14, 147-197 (1987).

43. Lobo, M. J., Miranda, A. J. \& Tunon, P. Amperometric biosensors based on NAD(P)-dependent dehydrogenase enzymes. Electroanalysis 9, 191-202 (1997).

44. Ren, N. Q., Li, J. Z., Li, B. K., Wang, Y. \& Liu, S. R. Biohydrogen production from molasses by anaerobic fermentation with a pilot-scale bioreactor system. Int. J. Hydrogen Energy 31, 2147-2157 (2006).

45. Finkel, T., Deng, C. X. \& Mostoslavsky, R. Recent progress in the biology and physiology of sirtuins. Nature 460, 587-591 (2009).
46. Palmore, G. T. R., Bertschy, H., Bergens, S. H. \& Whitesides, G. M. A methanol/ dioxygen biofuel cell that uses $\mathrm{NAD}(+)$-dependent dehydrogenases as catalysts: application of an electro-enzymatic method to regenerate nicotinamide adenine dinucleotide at low overpotentials. J. Electroanal. Chem. 443, 155-161 (1998).

47. Matsumoto, R. et al. A liposome-based energy conversion system for accelerating the multi-enzyme reactions. Phys. Chem. Chem. Phys. 12, 13904-13906 (2010).

48. Fujita, S. et al. Bioelectrocatalytic oxidation of glucose with antibiotic channelcontaining liposomes. Phys. Chem. Chem. Phys. 15, 2650-2653 (2013).

\section{Acknowledgments}

The authors wish to thank Ryuhei Matsumoto, Taiki Sugiyama, and Dr. Alok S. Tayi for helpful comments and discussion.

\section{Author contributions}

S.F. designed and performed the experiments, analysed the results, and prepared the manuscript. S.Y. prepared the key carbon materials and reviewed the manuscript. K.M. designed and performed the anode experiment, assisted the cell experiments, and reviewed the manuscript. H.M. designed and performed the music player experiments and reviewed the manuscript. T.S. performed the cell experiments and reviewed the manuscript. T.N. assisted the music player experiments, and reviewed the manuscript. H.S. and Y.T. assisted the experiments and reviewed the manuscript.

\section{Additional information}

Supplementary information accompanies this paper at http://www.nature.com/ scientificreports

Competing financial interests: The authors declare no competing financial interests. How to cite this article: Fujita, S. et al. A repeatedly refuelable mediated biofuel cell based on a hierarchical porous carbon electrode. Sci. Rep. 4, 4937; DOI:10.1038/srep04937 (2014).

This work is licensed under a Creative Commons Attribution-NonCommercialNoDerivs 3.0 Unported License. The images in this article are included in the article's Creative Commons license, unless indicated otherwise in the image credit; if the image is not included under the Creative Commons license, users will need to obtain permission from the license holder in order to reproduce the image. To view a copy of this license, visit http://creativecommons.org/licenses/by-nc-nd/3.0/ 